\title{
Taxonomic resolution needed to describe invertebrate assemblages and to detect harvesting effects on coral reef ecosystems
}

\author{
H. Jimenez ${ }^{1, *}$, P. Dumas ${ }^{1}$, L. Bigot ${ }^{2}$, J. M. Amouroux ${ }^{3}$, J. Ferraris ${ }^{4}$ \\ ${ }^{1}$ Institut de Recherche pour le Développement (IRD), Centre IRD de Noumea, BP A5, 98848 Noumea Cedex, New Caledonia \\ ${ }^{2}$ Laboratoire d'Ecologie Marine, ECOMAR, Université de La Réunion, Avenue René Cassin, BP 7151, \\ 97715 Saint Denis Cedex, Reunion Island, France \\ ${ }^{3}$ Laboratoire d'Océanographie Biologique de Banyuls, UMR 7621, CNRS-Université Paris VI, BP 44, \\ 66651 Banyuls-sur-Mer Cedex, France \\ ${ }^{4}$ Institut de Recherche pour le Développement (IRD), Université de Perpignan, 52 avenue Paul Alduy, 66860 Perpignan, France
}

\begin{abstract}
Due to the cost and time required for species identification, the taxonomic sufficiency approach has been developed in order to detect community response to a disturbance, using high taxonomic level without great loss of information. This concept has been widely applied to pollution monitoring studies but rarely to other forms of perturbations such as anthropogenic exploitation of marine resources. We applied this method both to soft-bottom (seagrasses) and hard-bottom (coralline) tropical invertebrate communities in New Caledonia, South Pacific. The objective was to test whether intermediate or high taxonomic levels (genus, family, class or phylum instead of species) are good descriptors of community patterns and changes in assemblages related to harvesting, by comparing harvested to non-harvested areas for the 2 habitats. We pooled species data into coarser taxonomic categories (from genus to phylum) and showed that matrices at different taxonomic resolutions were highly correlated, particularly for genus and family level for both habitats. Differences between harvested and non-harvested locations appeared to be clearly habitat-dependent; for soft habitats, genus and family resolution allowed the detection of changes between exploited and protected assemblages, while for hard habitats, the separation between harvested and non-harvested areas was less clear at high taxonomic level and required species-level identifications. These results suggest that the taxonomic sufficiency approach could be carefully applied to poorly known environments. Family level is a good descriptor of community composition for tropical reef invertebrates. Detecting changes due to anthropogenic exploitation requires different taxonomic resolutions depending on the considered habitat.
\end{abstract}

KEY WORDS: Taxonomic resolution · Data transformation · Tropical reef invertebrates · Harvesting effect $\cdot$ Marine protected areas

\section{INTRODUCTION}

Identifying the species that constitute a community is a general first step in conservation biology. Yet, for marine benthic invertebrates, monitoring plans require time, skills (Ferraro \& Cole 1995), and extensive knowledge about the local fauna (Warwick 1988). For example, in monitoring the effectiveness of marine protected areas (MPAs), several biological indicators based on species richness, densities and biomasses are usually recommended but others are more synthetic and pertinent parameters exist. One of them is the taxonomic sufficiency (TS) approach, developed to improve cost-effectiveness when describing spatial 
patterns (Ellis 1985), in particular for disturbancerelated changes in benthic communities (Somerfield \& Clarke 1995). This method uses coarser taxonomic levels when performing community comparisons, instead of species level. Several papers have addressed the validity of TS in marine ecosystems (Warwick 1988, Ferraro \& Cole 1990, 1992, 1995, Gray et al. 1990, Warwick \& Clarke 1993, Somerfield \& Clarke 1995, Karakassis \& Hatziyanni 2000). As well as a reduced need for taxonomic expertise, expected benefits include the removal of ecological redundancy attributed to the use of multiple species, when loss of information has no significant effect (Gray et al. 1988, Warwick 1988, 1993). Despite its increasing popularity on impact assessment, TS is still controversial (May 1990, Maurer 2000), in particular in the context of a global decline of taxonomic resources and species knowledge (Scheltema 1996, Boero 2001).

Most studies using TS were in marine benthic habitats, including temperate soft-bottom benthic communities such as coastal gravel and sandy beaches (James et al. 1995, Somerfield \& Clarke 1995, Vanderklift et al. 1996, Olsgard et al. 1998, Baldo et al. 1999, Rumohr \& Karakassis 1999, Dauvin et al. 2003, Gomez-Gesteira et al. 2003, Stark et al. 2003, Thompson et al. 2003, Defeo \& Lercari 2004), lagoons (Lardicci \& Rossi 1998, Mistri \& Rossi 2001, Arvanitidis et al. 2009), estuaries (MacFarlane \& Booth 2001, Roach et al. 2001, De Biasi et al. 2003) or deep-sea environments (Narayanaswamy et al. 2003). Hard-bottom systems have also been studied, e.g. rocky shores (Juanes \& Canteras 1995, Urkiaga-Alberdi et al. 1999, Pagola-Carte et al. 2002, Terlizzi et al. 2002, Anderson et al. 2005) and other temperate, coastal environments (Chapman 1998, Terlizzi et al. 2003).

These studies usually showed that analyses at higher taxonomic levels (most of the time family instead of species) do not necessarily result in a significant loss of information, and tend to better reflect perturbation gradients than those based on species abundances (Olsgard et al. 1997). This is especially true within pollution-related gradients, where the response of the assemblages is usually more evident at higher taxonomic levels (Warwick 1988, 1993). Yet, the use of coarser taxonomic resolution may not perform as well in different disturbance contexts. To date, only one study specifically investigated the performance of the TS approach on other types of disturbance (e.g. invertebrate exploitation), comparing rocky-shore communities in exploited and protected areas at different taxonomic resolutions (Lasiak 2003). Lasiak (2003) found that even though the data matrices at different taxonomic resolutions were strongly correlated, clear, significant differences between exploited and non-exploited assemblages only occurred at species level. In the latter case, anthropogenic exploitation changed the assemblages in a different way as it was essentially targeting a single group, the molluscs (Bigalke 1973, Lasiak 1992), therefore, resulting in differences in abundance rather than in species composition (Lasiak 1998).

In addition, the efficiency of TS may also vary depending on the objectives of the study, sampling protocol, statistical design and data transformation. In fact, comparisons of impacted and non-impacted assemblages require decisions about the level of taxonomic resolution to which organisms are identified as well as the transformation of data prior to statistical analysis. The effects of data transformation can be as important as the taxonomic level to which organisms are identified (Clarke \& Green 1988, Olsgard et al. 1997, 1998, Legendre \& Gallagher 2001, Anderson et al. 2005). In multivariate analyses, the raw data transformation thus determines the aspect of the assemblage that is emphasised and can affect the outcome of analyses, in particular when data are aggregated at higher taxonomic levels (Olsgard et al. 1998, Karakassis \& Hatziyanni 2000). When raw (untransformed) data are used, the focus is only on common taxa, while when severe 4th-root transformation is used, as recommended by Field et al. (1982), the focus shifts to all of the species constituting the assemblage (Clarke \& Warwick 1994).

In the tropics and coral reef environments, data supporting the TS approach remain scarce and concern changes in soft-bottom macrofauna due to pollution in coastal embayments (Agard et al. 1993), coastal and deep continental shelfs (Guzman \& Garcia 1996, Guzman-Alvis \& Carrasco 2005), estuaries (Torres Mendes et al. 2007) and subtidal environments (Gray 2002). No studies specifically addressed the efficiency of TS on tropical hard- and soft-bottom communities in the context of MPA management.

The main objective of the present study was therefore to assess how decisions about taxonomic resolution and data transformation influence (1) the ability to accurately describe community structure and composition, and (2) the efficiency in detecting differences between exploited and non-exploited tropical invertebrates communities, in contrasted (hard vs. soft) reef environments. It was expected that this pilot study would provide results and recommendations to detect and measure particular anthropogenic perturbation of tropical scarcely known invertebrate assemblages.

\section{MATERIALS AND METHODS}

Study area. This study was carried out in New Caledonia, southwest Pacific $\left(166^{\circ} \mathrm{E}, 22^{\circ} \mathrm{S}\right)$, characterised by a large lagoon covering an area of $19000 \mathrm{~km}^{2}$, with 
numerous patch reefs, islets and fringing reefs. In New Caledonia, coastal and islet reef flats have been subjected to human exploitation for centuries, mainly through traditional reef-top gathering. Fishing pressure increased in the last few decades due to the growing urbanisation around Noumea city (Fig. 1). To conserve biodiversity and to sustainably manage marine resources in the New Caledonian lagoon, MPAs were implemented in the 1990s, mainly located in the southwest lagoon around Noumea. In this zone, intertidal reef flats cover $13 \%$ of the area, where invertebrate harvesting (i.e. collecting) activity is essentially noncommercial (Baron \& Clavier 1992). Harvesting invertebrates traditionally occurs at low tide when intertidal fauna is accessible. Yet, few quantitative data are available on the spatio-temporal dynamics of har- vesting activities and their impact on reef benthic communities.

Eight stations were chosen in the southwest lagoon around Noumea (Fig. 1); 4 of them are exploited stations, and the other 4 stations are non-exploited (MPAs). In addition, interviews with harvesters allowed us to estimate the annual harvesting pressure on coastal and islets reef flats (Table 1).

Habitat characteristics. Our chosen intertidal stations are subject to semi-diurnal tides (with maximum amplitude of $1.8 \mathrm{~m}$ ) and oriented in front of a general hydrodynamic flow (from southeast to the northwest current). Two contrasted habitats (i.e. biotopes) were considered: hard-bottom and soft-bottom environments, with different harvested species $(\mathrm{H}$. Jimenez unpubl. data). The description of coral reef habitats

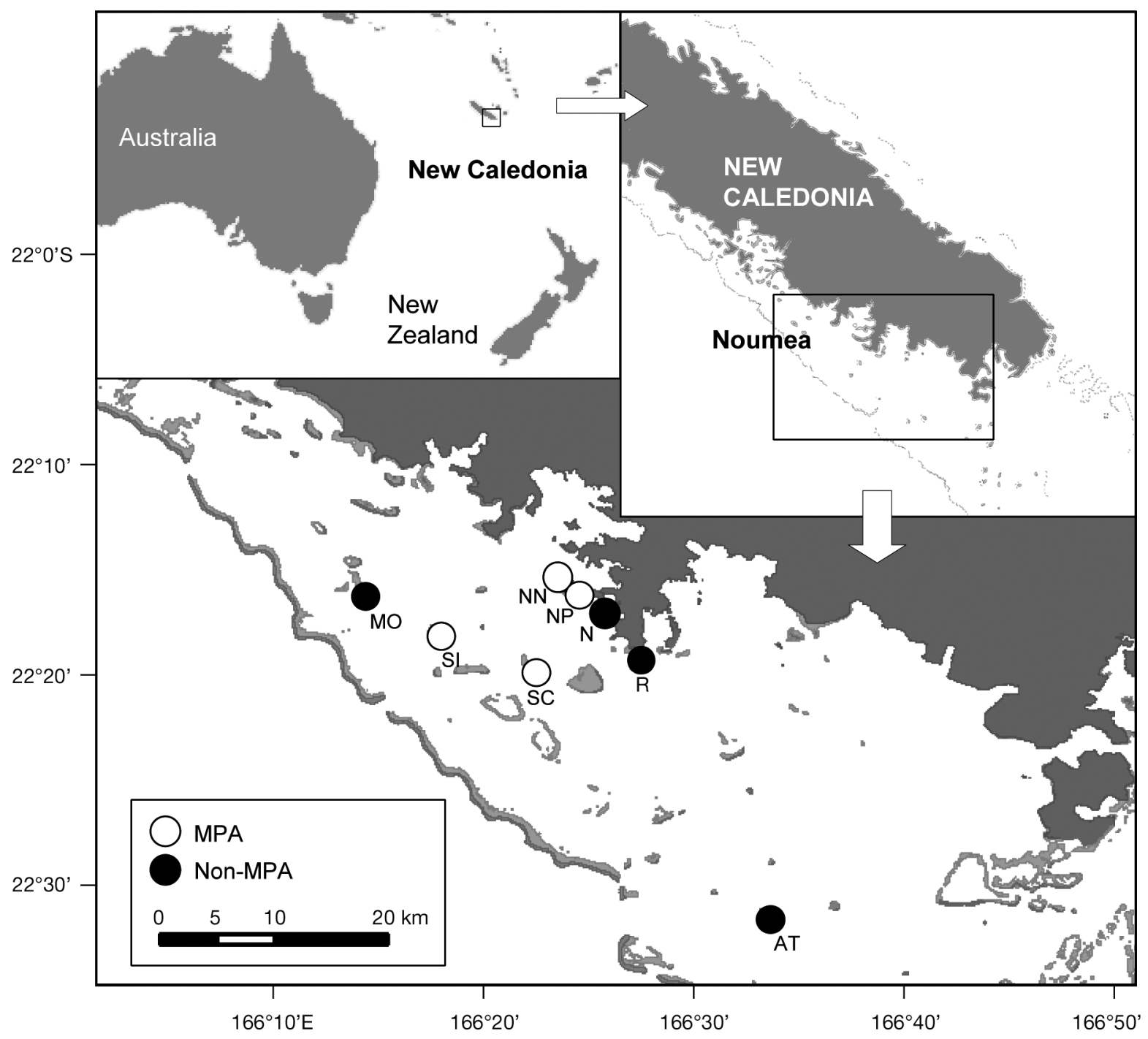

Fig. 1. Study area and sampling stations. Islet reef flats (MO: Mbo, SI: Signal, SC: Sèche-croissant, AT: Atire) present hard-bottom habitats and coastal reef flats (N: Nouville 1, NP: Nouville 2, NN: Nouville 3, R: Ricaudy) soft-bottom habitats. MPA: marine protected area 
was assessed by a photographic method allowing quantitative estimation of percentage covers of different benthic categories (see Dumas et al. 2009). The soft-bottom habitat was mainly characterised by the seagrasses Cymodocea serrulata and Halodule uninervis ( 62\%), green (genera Halimeda, Ulva, Codium) and brown (Padina sp., Sargassum spp., Turbinaria ornata) algae ( 22\%) and sand ( 16\%). The hard-bottom habitat was essentially made up of dead corals, boulders or debris $(\sim 82 \%)$, encrusting algae $(\sim 13 \%)$, some live corals $(\sim 4 \%)$ and sponges $(\sim 1 \%)$. Benthic assemblages from these habitats were compared between harvested and non-harvested sites (Table 1).

Faunal sampling. Field studies were conducted in summer 2009, during 8 successive days in March. Intertidal macrofauna and megafauna assemblages (excluding nematodes, bryozoans, flatworms and nemerteans) were sampled during low tides when invertebrates were the most accessible, in the following 2 ways:

(1) Soft-bottom macrofauna was sampled by sieving sand and seagrasses on 5 randomly placed replicates per station accounting for a total of 20 samples. Grabs of $0.1 \mathrm{~m}^{2}$ circumference pushed in $30 \mathrm{~cm}$ sediment depth were used; sand, seagrasses and associated fauna were removed with a shovel, immediately sieved on a $1 \mathrm{~mm}$ round mesh, fixed in $5 \%$ formalin and conserved in plastic bags. In the laboratory, all individuals coloured using Rose Bengal were separated from the sediment under a binocular microscope; counting and identification were then performed. All individuals were identified to the lowest possible taxonomic level, which in $85 \%$ of cases was species level.

(2) Hard-bottom fauna was sampled by hand along 5 randomly placed belt transects $(20 \times 2 \mathrm{~m})$; all visible mobile and sessile epibenthic invertebrates (megafauna $>1 \mathrm{~cm}$ ) were collected, and later conserved frozen, in plastic bags. This method allows the sampling of visible and cryptic fauna encountered behind large tabular corals without disturbing the habitat.

Table 1. Sampling stations (see Fig. 1), reef flat typology, status for collecting invertebrates with associated harvesting pressure (H. Jimenez unpubl. data), and reference habitats. MPA: marine protected area

\begin{tabular}{|lcccc|}
\hline Stn & $\begin{array}{c}\text { Reef } \\
\text { flat } \\
\text { typology }\end{array}$ & $\begin{array}{c}\text { Status } \\
\text { (implementation } \\
\text { year) }\end{array}$ & $\begin{array}{c}\text { No. of } \\
\text { harvests } \\
\mathrm{yr}^{-1}\end{array}$ & Habitat \\
\hline Ricaudy (R) & Coastal & Harvested & 1300 & Soft-bottom \\
Nouville 1 (N) & Coastal & Harvested & 1300 & $\begin{array}{l}\text { Soft-bottom } \\
\text { Nouville 2 (NP) }\end{array}$ \\
Coastal & MPA (1998) & 0 & Soft-bottom \\
Nouville 3 (NN) & Coastal & MPA (1998) & 0 & Soft-bottom \\
Atire (AT) & Islet & Harvested & 600 & Hard-bottom \\
Mbo (MO) & Islet & Harvested & 600 & Hard-bottom \\
Signal (SI) & Islet & MPA (1989) & 0 & Hard-bottom \\
Sèche-croissant (SC) Islet & MPA (1994) & 0 & Hard-bottom \\
\hline
\end{tabular}

Then identifications were done in the laboratory under a binocular microscope and individuals were conserved in $70 \%$ alcohol. All individuals were identified to the lowest possible taxonomic level, which in $95 \%$ of cases was species level.

Data analysis. The influence of taxonomic resolution and data transformation on the description of community composition was assessed. From the initial species and stations table, new data matrices were created by aggregating raw data at increasingly higher taxonomic levels (genus, family, class and phylum). The following transformations were applied to each resulting matrix: none, square root, 4 th root, $\log (x+1)$ and presence or absence. Consequently, 25 matrices were obtained for each habitat (see Table 2). These data were investigated using multivariate techniques, following 2 different steps. (1) Similarities based on Bray-Curtis coefficients were calculated between the data matrices at different taxonomic levels, using Spearman rank correlations with associated levels of significance (see RELATE procedures from Clarke \& Ainsworth 1993). The Rho statistic and the p-value indicate the similarity value and significance respectively of these correlations. (2) Multivariate ordination of MPA versus non-MPA replicates per station based on faunal variables was performed using non-linear multidimensional scaling (MDS) for each taxonomic level and data transformation. The adequacy of the spatial representation was assessed using a stress value considered correct when it is $<0.20$ (see Clarke \& Warwick 1994). A 2-dimensional representation was generated for each habitat (soft vs. hard) from these 25 similarity matrices, using 'second stage' non-linear MDS procedures (see Somerfield \& Clarke 1995, Olsgard et al. 1997, 1998).

Next, the ability to detect changes in community structure between harvested versus non-harvested areas was tested with multivariate analysis of similarities (ANOSIM). The R statistic gives the degree of separation of sites and the p-value indicates significance.

All data analyses were performed using PRIMER routines (Clarke \& Warwick 1994).

\section{RESULTS}

\section{Species assemblages}

In the 8 sampled stations from the 2 habitats, 6075 individuals belonging to 242 species were recorded. The fauna from soft- and hard-bottom habitats differed markedly, with only 17 common species in both habitats. Due to these clear differences between hard- 
and soft-bottom assemblages, the following analyses were done separately.

From the soft habitats, a total of 107 species, belonging to 76 genera, 55 families, 14 classes and 7 phyla were identified (Table 2). Twenty species were harvested, representing $18.7 \%$ of the biodiversity and $18.9 \%$ of the abundances. Molluscs accounted for $34 \%$ of the collected individuals, followed by annelids $(23 \%)$, echinoderms (21\%), arthropods (11\%) and other taxa (11\%) (Fig. 2A). The most speciose phylum was the molluscs, with $42 \%$ of the total species, followed by arthropods (21\%) and annelids (20\%). The most frequent species were the ophiurid Ophiactis savigny (Müller and Troschel, 1842), the buried bivalves Gafrarium tumidum Röding, 1798 and Anadara scapha (Linnaeus 1758), the gastropod Phasianella variegata (Lamarck, 1822) and the worm Bhawania cryptocephala (Gravier, 1902). They accounted for $34 \%$ of the total abundance, while $70 \%$ was represented by the top 21 dominant species (Fig. 2A). Among them, only the buried bivalves are commonly harvested species while the others are usually not targeted by fishers.

From the hard habitats, a total of 152 species belonging to 92 genera, 65 families, 13 classes and 5 phyla were identified (Table 2). Twenty-seven species were harvested, representing $17.7 \%$ of the biodiversity and $21.2 \%$ of the abundances. Molluscs accounted for $54 \%$ of the sampled individuals, arthropods $34 \%$, echinoderms $9 \%$ and the remaining taxa 3\% (Fig. 2B). The

Table 2. Number of taxonomic units at each level of taxonomic resolution and data matrix (taxonomic units $\times$ transformations) per habitat

\begin{tabular}{|lcc|}
\hline Taxonomic unit & Soft substrata & Hard substrata \\
\hline Species & 107 & 152 \\
Genus & 76 & 92 \\
Family & 55 & 65 \\
Class & 14 & 13 \\
Phylum & 7 & 5 \\
Data matrix & $5 \times 5=25$ & $5 \times 5=25$ \\
\hline
\end{tabular}

A

\section{Mollusca \\ Annelida \\ $\square$ Echinodermata \\ $\square$ Arthropoda \\ $\square$ Cnidaria \\ $\square$ Spongia \\ $\square$ Sipunculida}

B

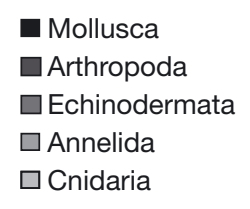

Mollusca

Arthropoda

$\square$ Annelida

$\square$ Cnidaria
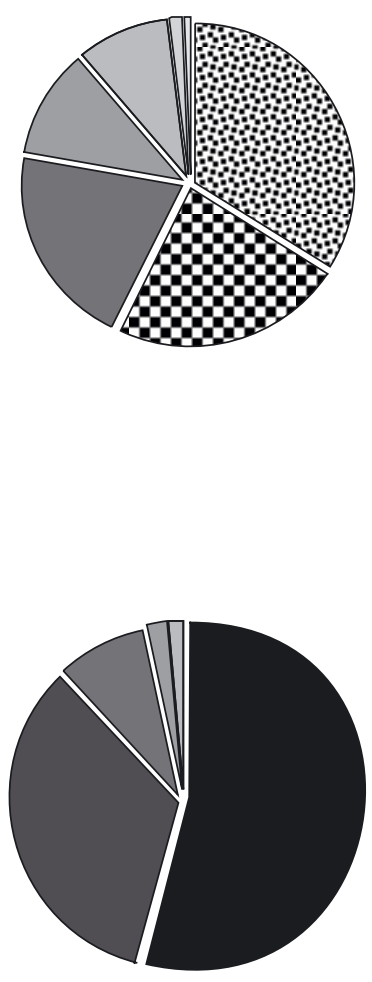
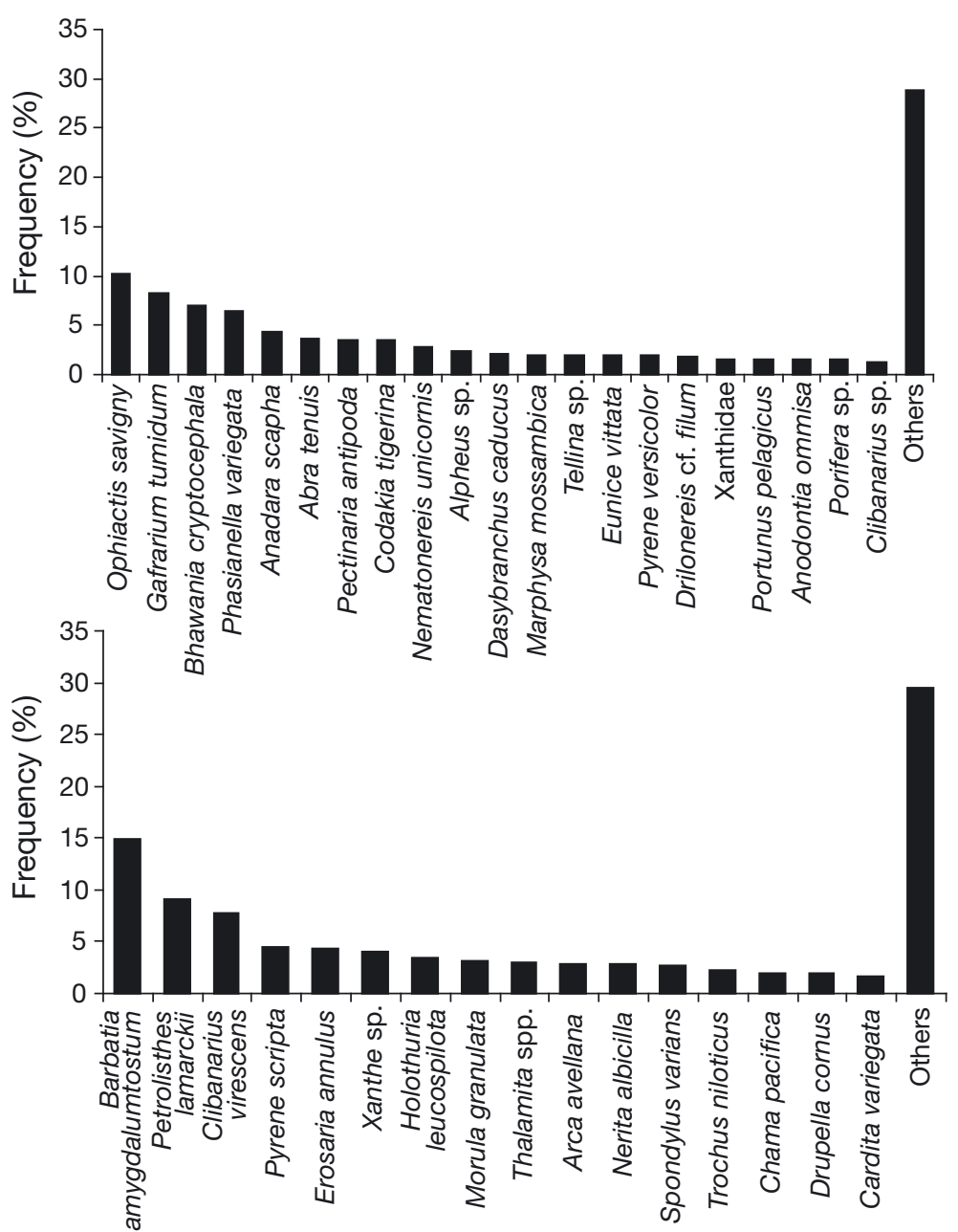

Fig. 2. Contribution (\%) of each phylum and species occurrence for (A) soft- and (B) hard-bottom fauna 
Table 3. Correlations between pairs (species and all other taxonomic levels) of similarity matrices at different taxonomic resolutions and data transformations for soft- and hard-bottom habitats. Values are Spearman's rho statistic. ${ }^{*} \mathrm{p}<0.05 ;{ }^{* *} \mathrm{p} \leq 0.01 ;{ }^{* * *} \mathrm{p} \leq 0.001$

\begin{tabular}{|c|c|c|c|c|c|c|}
\hline \multirow{2}{*}{ Habitat } & \multirow{2}{*}{ Taxonomic level } & \multicolumn{5}{|c|}{ - Transformation } \\
\hline & & None & Square root & 4 th root & $\log (x+1)$ & Presence or absence \\
\hline \multirow[t]{4}{*}{ Soft } & Genus & $0.98^{* * *}$ & $0.97^{* * *}$ & $0.96^{* * *}$ & $0.95^{* * *}$ & $0.94^{* * *}$ \\
\hline & Family & $0.95^{* * *}$ & $0.95^{* * *}$ & $0.92^{* * *}$ & $0.91^{* * *}$ & $0.89^{* * *}$ \\
\hline & Class & $0.85^{* * *}$ & $0.83^{* * *}$ & $0.80^{* * *}$ & $0.85^{* * *}$ & $0.72^{* * *}$ \\
\hline & Phylum & $0.79^{* * *}$ & $0.78^{* * *}$ & $0.77^{* * *}$ & $0.75^{* * *}$ & $0.71^{* * *}$ \\
\hline \multirow{4}{*}{ Hard } & Genus & $0.98^{* * *}$ & $0.96^{* * *}$ & $0.93^{* * *}$ & $0.92^{* * *}$ & $0.86^{* * *}$ \\
\hline & Family & $0.93^{* * *}$ & $0.92^{* * *}$ & $0.91^{* * *}$ & $0.90^{* * *}$ & $0.76^{* * *}$ \\
\hline & Class & $0.83^{* * *}$ & $0.80^{* * *}$ & $0.69^{* *}$ & $0.65^{* *}$ & $0.45^{* *}$ \\
\hline & Phylum & $0.78^{* * *}$ & $0.76^{* * *}$ & $0.65^{* *}$ & $0.60^{* *}$ & $0.14^{*}$ \\
\hline
\end{tabular}

main phylum was the molluscs (56\% of species) followed by arthropods (23\%) and echinoderms (14\%). The most frequent species were the bivalve Barbatia amygdalumtostum (Röding, 1798), the spotted halfcrab Petrolisthes lamarckii (Leach, 1820), the hermitan crab Clibanarius virescens (Krauss, 1843), and the gastropods Pyrene scripta (Lamarck, 1822) and Erosaria annulus (Linnaeus, 1758). These 5 non-targeted species accounted for $40 \%$ of the total abundances, while $70 \%$ was represented by the top 16 dominant species (Fig. 2B). The first targeted species Trochus niloticus (Linnaeus, 1767) appears only at the 14th rank.

In both habitats, invertebrate assemblages showed high diversity, and targeted species constituted a minor part of the community.

\section{Influence of taxonomic resolution and data transformation}

First, the invertebrate assemblage structures were compared at different taxonomic resolutions. The correlation between matrices at species level and higher taxonomic resolution was generally high; Spearman rank correlation ranged from 0.71 to 0.98 in softbottom habitats, and from 0.14 to 0.98 in hard-bottom habitats (Table 3). These correlations decreased from genus to phylum, whatever the data transformation and habitat considered. On the whole, Spearman coefficients were highly significant $(>0.90)$ for genera and families except for presence-absence data. Correlation scores dropped down below 0.80 for class and phylum levels. The decrease was much stronger for hard-bottom data with increasing severity of data transformation.

The correlation patterns among matrices were visualised through 2nd stage MDS (Fig. 3). A similar pattern was observed for soft- and hard-bottom macrofauna; a horizontal, taxonomic separation could be distinguished on the diagram with species, genus and family levels on the right side while class and phylum were located on the left. These 2 groups were significantly different in hard-bottom (ANOSIM: $\mathrm{R}=0.745$, $\mathrm{p}=0.0001$ ) and soft-bottom (ANOSIM: $\mathrm{R}=0.774, \mathrm{p}=$ 0.0001 ) habitats. In the same way, a vertical succession from raw (on the top) to severely transformed data (on the bottom) was clearly evident, whatever the taxonomic level considered. The same pattern was observed in the 2 habitats, with the exception of phylum taxonomic resolution in soft-bottom substrata. Stress values were correct $(0.12$ and 0.07 for soft- and hardbottom habitats respectively) corresponding to a good ordination of taxonomic resolution-data transformations pairs of matrices in a 2-dimensional space.

Next, changes mainly related to the exploitation of invertebrate assemblages were tested by comparing harvested to non-harvested areas at different taxonomic resolutions. Investigating the differences in species composition between assemblages from these areas emphasised much stronger differences in softbottom habitats, compared to hard-bottom habitats (ANOSIM; Table 4). Yet in both cases the ability to discriminate between assemblages (harvested vs. nonharvested) decreased with levels of taxonomic aggregation and the severity of data transformation.

In soft habitats, differences between assemblages were significant at all taxonomic levels, except for presence-absence data at class and phylum levels. Significance decreased from species to phylum, along with data transformation (R-statistic values dropping down from 0.52 to 0.05$)$. The corresponding MDS highlighted a clear distinction between harvested to non-harvested stations, with similar patterns at species, genus and family taxonomic levels (cf. Fig. 4). The distinction became less clear for heavily transformed data $([\log (x+1)]$ and presence-absence). While nonharvested stations were close to each other, harvested ones constituted 2 separated groups, with Stn R located far from the other stations, highlighting the special feature of Stn R. Stress values ranged from 0.02 to 0.20 , with a decrease from species to phylum emphasising lower discrimination at coarser taxonomic levels. 


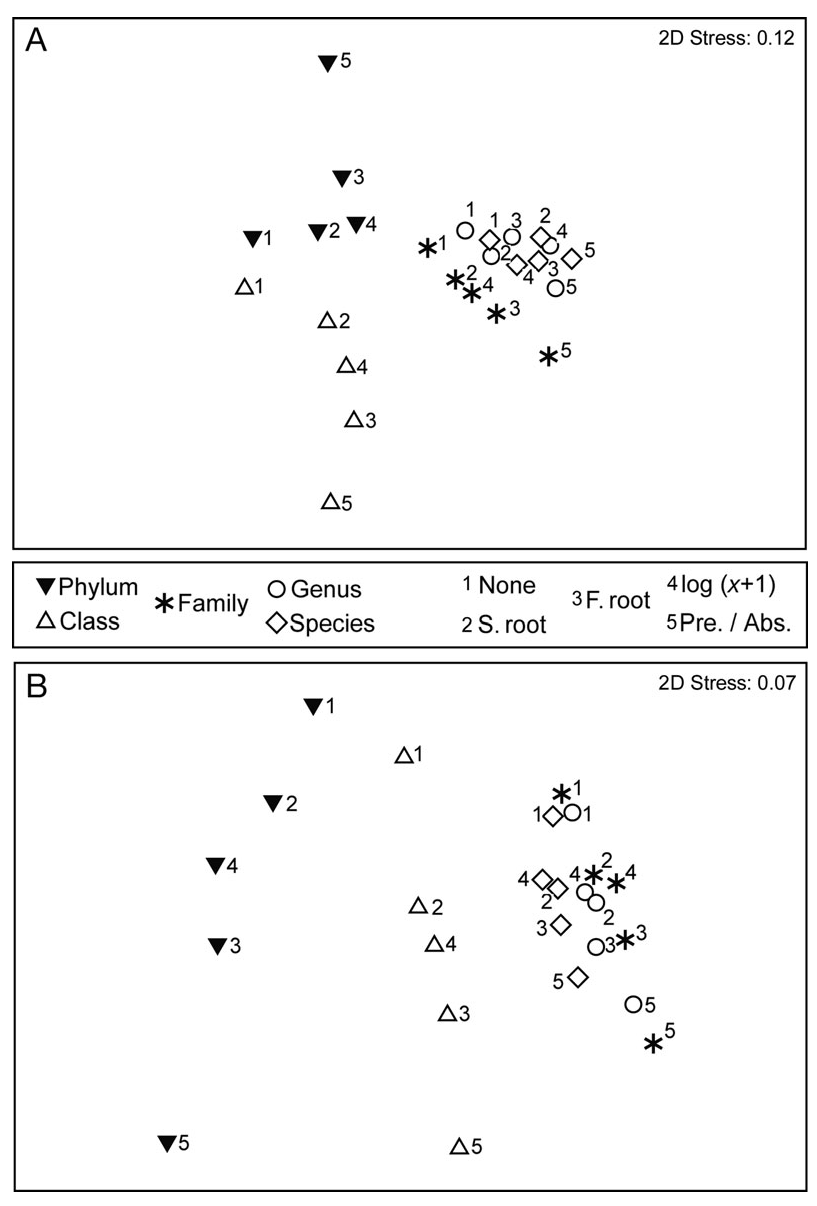

Fig. 3. Second-stage MDS from similarity matrix for all taxonomic resolution and data transformations in (A) soft- and (B) hard-bottom habitats. Each similarity matrix is defined by a symbol for taxonomic resolution and a numerical code for data transformation (1: none, 2: square root, 3: 4th root, 4: $\log (x+1), 5$ : presence or absence)

Table 4. Differences between harvested and non-harvested stations at different taxonomic resolution and data transformations for each habitat (soft- and hard-bottom. Values of R-statistic from one-way ANOSIM. ${ }^{*} \mathrm{p}<0.05 ;{ }^{* *} \mathrm{p} \leq 0.01$; ${ }^{* * *} \mathrm{p} \leq 0.001$

\begin{tabular}{|lllllll|}
\hline Habitat & Transformation & Species & Genus & Family & Class & Phylum \\
\hline \multirow{2}{*}{ Soft } & None & $0.52^{* * *}$ & $0.47^{* * *}$ & $0.45^{* * *}$ & $0.44^{* *}$ & $0.44^{* *}$ \\
& Square root & $0.45^{* * *}$ & $0.40^{* * *}$ & $0.41^{* *}$ & $0.40^{* *}$ & $0.37^{* *}$ \\
& 4th root & $0.35^{* *}$ & $0.31^{* *}$ & $0.29^{* *}$ & $0.22^{*}$ & $0.21^{*}$ \\
& Log $(x+1)$ & $0.31^{* *}$ & $0.27^{* *}$ & $0.24^{* *}$ & $0.21^{*}$ & $0.20^{*}$ \\
& Presence or absence & $0.28^{* *}$ & $0.22^{* *}$ & $0.19^{*}$ & 0.05 & 0.10 \\
Hard & & & & & \\
& None & $0.26^{* *}$ & $0.25^{* *}$ & $0.20^{* *}$ & 0.17 & 0.16 \\
& Square root & $0.24^{* *}$ & $0.23^{* *}$ & $0.22^{* *}$ & 0.17 & 0.15 \\
& 4th root & $0.23^{* *}$ & 0.19 & 0.18 & 0.16 & 0.14 \\
& Log $(x+1)$ & $0.22^{* *}$ & 0.17 & 0.16 & 0.10 & 0.09 \\
& Presence or absence & $0.21^{* *}$ & 0.16 & 0.15 & 0.09 & 0.02 \\
& & & & & \\
\hline
\end{tabular}

In hard habitats, the distinction between harvested and non-harvested areas was significant at species, genus and family taxonomic resolutions for raw or roughly transformed data only. Significance decreased at high taxonomic resolutions, along with data transformation. For heavily transformed data (4th root, log $(x+1)$ and presence-absence), differences between assemblages from harvested versus non-harvested sites could thus be discerned only at fine (i.e. species) taxonomic resolution (Fig. 5) with low R-statistic values but still highly significant (cf. Table 4). Compared to soft habitats, MDS plots showed rather fuzzy patterns for harvested versus non-harvested hard-bottom habitats. All stations were generally grouped, with harvested sites exhibiting higher dispersion. Stress values ranged from 0.00 to 0.21 and generally decreased from species to phylum, which enhanced the spatial representation at high taxonomic resolution.

\section{DISCUSSION}

TS is a pragmatic concept in which the accuracy of identification is balanced against the need for information (Ellis 1985). It is of growing concern for impact assessment studies as it strongly increases the cost-effectiveness of fauna identification. The TS theory relies on the use of high taxonomic levels as one of the best proxies of community composition, e.g. to efficiently detect disturbances in community structure, without crucial loss of information. Indeed, according to Warwick (1988), anthropogenic effects modify community composition at a higher taxonomic level than natural disturbances, influencing species replacement more than the proportion of taxa. In fact, as stress increases, the adaptability of first the individual, then the species, genus, family, class and phylum is exceeded (Ferraro \& Cole 1990). Following this observation, most of the studies conducted with temperate macrofauna showed that the family taxonomic level could be considered as a good predictor of community changes in response to anthropogenic disturbance (e.g. Ferraro \& Cole 1990, 1995, Olsgard et al. 1998, Olsgard \& Somerfield 2000, Roach et al. 2001, Gomez-Gesteira et al. 2003, Thompson et al. 2003, Guzman-Alvis \& Carrasco 2005, Terlizzi et al. 2009). Also, this theory is related to the data transformation which defines how different species constituting the community are taken into account.

The present paper is the first attempt to apply the TS approach in the context 


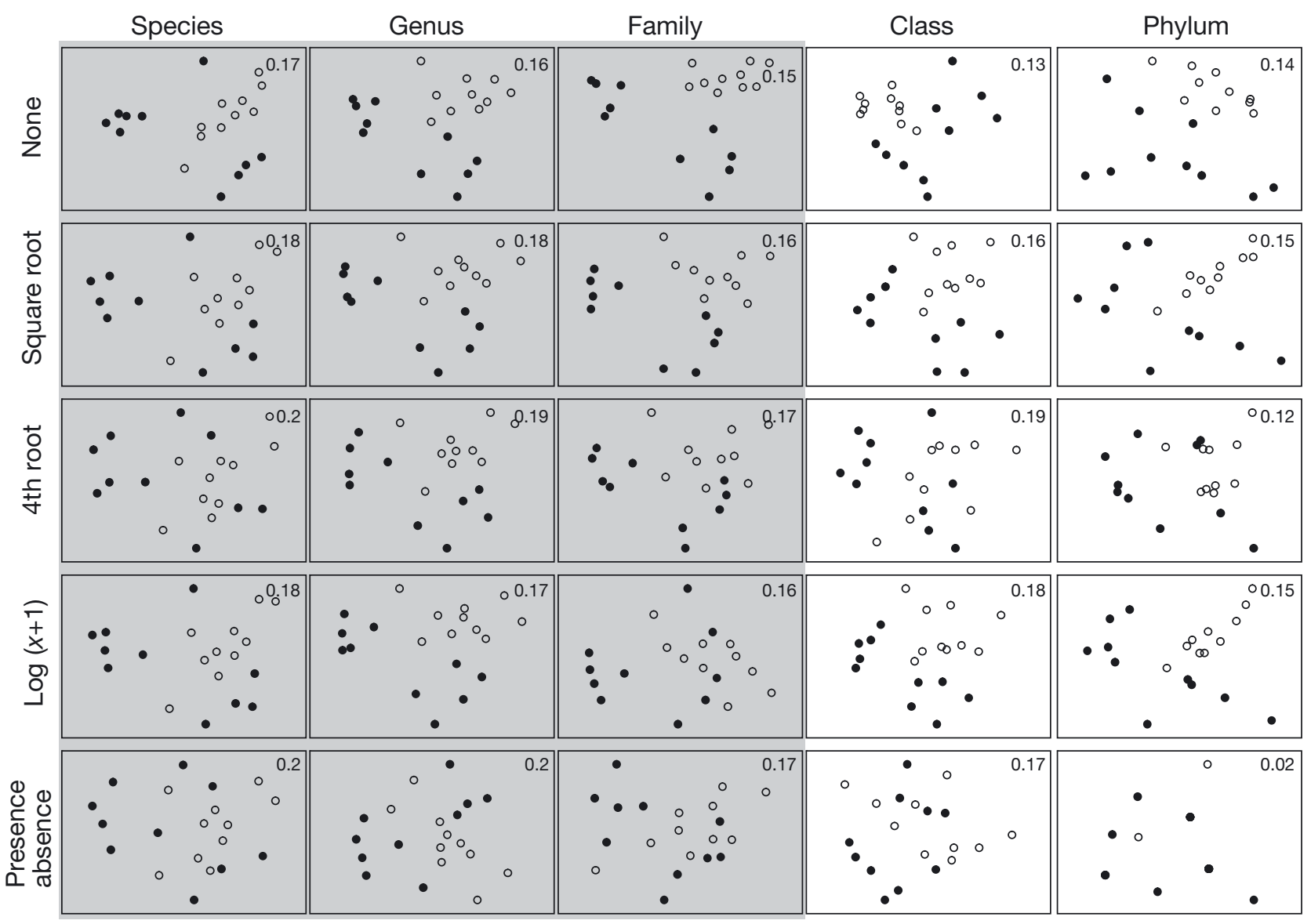

Fig. 4. MDS plots of harvested (•) and non-harvested (০) stations for different taxonomic resolutions and data transformations for soft-bottom habitats. Stress values are given. The boundary of distributions representing significant differences between harvested and non-harvested locations for a given taxonomic resolution and data transformation is matched by the grey area

of tropical marine invertebrates subjected to an anthropogenic perturbation, i.e. the harvesting of reef species. Quantitative data at species level on tropical reef macrofauna remain scarce, especially those that include all communities (i.e. hard- and soft-bottom habitats). In this context, the main goal of the present study was therefore to define the optimal taxonomic resolution and data transformation needed to (1) provide a good description of (local) reef flats benthic communities, and (2) detect changes between harvested and non-harvested invertebrate communities in 2 contrasted (hard vs. soft bottom) poorly known environments. The consequences of using high taxonomic resolution on the description of community and detection of these changes are also discussed.

\section{Characterising reef invertebrate assemblages at different taxonomic resolution}

The studied reef flat benthic communities were characterised by a higher number of species and individu- als sampled in hard-bottom habitats than in soft ones, but with higher density and species richness in softbottom assemblages. Both habitats were dominated by mollusc species, which represented more than onethird and one-half of total abundance in soft- and hardbottom habitats, respectively. Harvested species represented almost $20 \%$ of the abundances in the community and so ideally, studies addressing the impacts of harvesting on tropical invertebrate communities might therefore encompass the whole assemblage (e.g. using the TS approach to increase cost-effectiveness), rather than focusing on a few preselected species. Nevertheless, these 2 habitats were represented by contrasted benthic communities which have only 17 common species, slightly less than $7 \%$ of total biodiversity. Taxonomic aggregation could thus be expected to have different effects on hard- and softbottom communities.

Considering the description of invertebrate assemblages, we showed that on the whole, taxonomic aggregation had different consequences in the 2 studied habitats: while correlations between the faunal matri- 


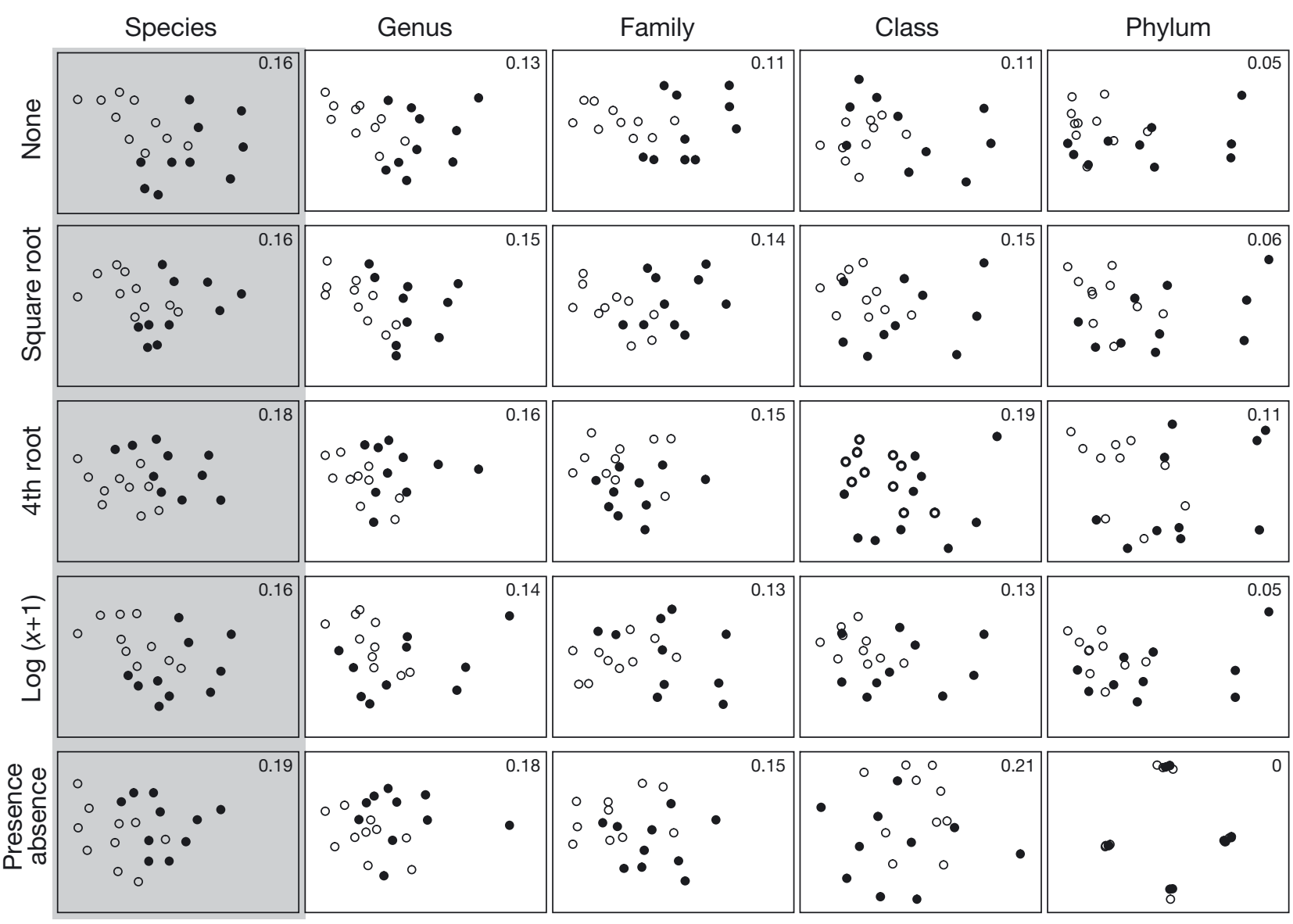

Fig. 5. MDS plots of harvested $(\bullet)$ and non-harvested (০) stations for different taxonomic resolutions and data transformations for hard-bottom habitats. Stress values are given. The boundary of distributions representing significant differences between harvested and non-harvested locations for a given taxonomic resolution and data transformation is matched by the grey area

ces always decreased with higher taxonomic levels and the severity of data transformation, the decrease was generally much stronger for invertebrate assemblages from hard-bottom reef habitats. This is probably due to higher taxon decreases between each taxonomic resolution in hard-bottom habitats than in soft ones. Yet, correlations were always higher than 0.90 at genus and family levels. This is related to the poor number of species per genus and genera per family, which is one of the main requirements for an effective utilisation of the TS approach (Somerfield \& Clarke 1995). Thompson et al. (2003) considered that differences became blurred when correlations fell below 0.90 and results from 2 nd stage MDS clearly emphasise the separation of species, genus and family matrices from class and phylum; working at family level thus appears to be a relevant surrogate of reef-community composition for the studied area. In both habitats, the practical benefits of working at coarser taxonomic resolutions include enhanced cost-benefits ratios, allowing sampling optimisations through additional replicates, control locations or periods (Thompson et al. 2003). In poorly known, highly diverse ecosystems such as tropical reef flats, TS may therefore constitute an efficient, pragmatic approach suitable for a variety of studies addressing benthic invertebrates. For a rapid and efficient description of tropical intertidal assemblages when little information is available, family level can give a good picture of spatial patterns. Nevertheless, it should be kept in mind that assemblage knowledge at species level is a first key step before trying to define the optimal taxonomical level for routine monitoring studies (Terlizzi et al. 2003). The TS approach is clearly efficient when species-level baseline studies have already been completed (Olsgard \& Somerfield 2000), and should always be cautiously framed within a given context (e.g. study objectives, sampling design).

\section{Using TS to detect harvesting-related changes in tropical reef communities}

The comparison of benthic communities showed different species composition between harvested and non- 
harvested areas. Generally, taxonomic aggregation decreases the ability of ANOSIM to detect disturbance effects, by smoothing differences between impacted and control areas (Somerfield \& Clarke 1995, Lardicci \& Rossi 1998, Pagola-Carte et al. 2002). In the same way, the present study showed that the MDS stress values usually decreased with lower taxonomic resolution. According to Somerfield \& Clarke (1995), this is due to the reduction of heterogeneity among species averaging harvest effects and inter-sample relationships.

Despite these general trends, our results emphasised that differences in assemblage structure of harvested versus non-harvested stations were detected at different levels of taxonomic aggregation. In soft-bottom habitats, stations clearly differed at all taxonomic resolution as a consequence of very poor numbers of species per genus and of genera per family and to the homogeneity of invertebrate assemblages. Differences decreased with the severity of data transformations but were maintained from species to phylum. Combining taxonomic resolution, data transformation and correlations between matrices, we showed that family level in all data transformations gave good results for detecting differences between harvested and non-harvested assemblages in soft-bottom habitats.

In contrast, the separation between harvested and non-harvested areas was less clear in hard-bottom habitats. In the latter case, the effects of data transformation were higher than those of taxonomic resolution, consistent with Olsgard et al. $(1997,1998)$ and Anderson et al. (2005). While data transformation shifts the emphasis from common taxa to the entire community, it has major consequences for assemblages where most species are relatively rare (as in the present study). In this case, Field et al. (1982) suggest to use 4th root transformed data, which is equivalent to reducing abundance to a scale of $0=$ absent, $1=1$ individual, 2 = a few individuals, 3 = several individuals, 4 = abundant and $\geq 5$ = very abundant (Clarke \& Warwick 1994). Indeed in the present study, using transformed (including 4 th root transformed) rather than raw data yielded lower discrimination between group samples. Differences between harvested and nonharvested assemblages probably due to harvesting effects were hardly detectable at aggregation levels higher than species, suggesting that for specific habitats (i.e. hard-bottom in the present study), family level does not perform well as a species surrogate (Bowman \& Bailey 1997, Narayanaswamy et al. 2003). This can be linked to the poor density and species richness of hard-bottom assemblages which constrain the detection of differences between sites to the lowest (i.e. species) taxonomic resolution. Working at a higher taxonomic level in this case can blur the evidence of changes related to the exploitation disturbance.
To conclude, the present study gives some recommendations about the characterisation of poorly known tropical invertebrate assemblages in the context of marine resources management. The family level seems to be a good descriptor of invertebrate community composition for tropical reef (hard- and soft-bottom) environments when assemblages are already known. Nevertheless, changes related to anthropogenic exploitation were only clearly evident at species level for hard-bottom communities. While these results emphasise that harvesting impacts were clearly habitatdependent, more work is still required in a wider array of environmental contexts to derive general recommendations for tropical, macrobenthic invertebrates. Now that this initial methodological step is achieved, expanding the spatial and temporal coverage of the present study will allow us to address the ecological implications of the observed alterations in invertebrate assemblages caused by harvesting activities.

Acknowledgements. We extend our gratitude to G. Chapman for helpful comments about sampling design. We are grateful to J. Baly and C. Peignon who assisted us in the field. We thank M. Tavares, J. Poupin, E. Tardy, C. Berthault and R. Von Cosel for the contributed help in identification of the species. C. Labrune is acknowledged for helpful comments and suggestions about the manuscript. We also thank the reviewers, whose comments greatly improved the manuscript. This research was supported by the CRISP, PAMPA and GAIUS programmes and by a PhD grant from Eusko Jaurlaritza/Gobierno Vasco.

\section{LITERATURE CITED}

Agard JBR, Gobin J, Warwick RM (1993) Analysis of marine macrobenthic community structure in relation to pollution, natural oil seepage and seasonal disturbance in a tropical environment (Trinidad, West Indies). Mar Ecol Prog Ser 92:233-243

Anderson MJ, Connell SD, Gillanders BM, Diebel CE, Blom WM, Saunders JE, Landers TJ (2005) Relationships between taxonomic resolution and spatial scales of multivariate variation. J Anim Ecol 74:636-646

Arvanitidis C, Somerfield J, Chatzigeorgiou G, Reizopouiou $\mathrm{S}$, Kevrekidis T, Eleftheriou A (2009) Do multivariate analyses incorporating changes in pattern across taxonomic levels reveal anthropogenic stress in Mediterranean lagoons? J Exp Mar Biol Ecol 369:100-109

Baldo F, Garcia-Martin SF, Drake P, Arias AM (1999) Discrimination between disturbed coastal ecosystems by using macrobenthos at different taxonomic levels. Bol Inst Esp Oceanogr 15:489-493

Baron J, Clavier J (1992) Estimation of soft-bottom intertidal bivalve stocks on the south-west of New Caledonia. Aquat Living Resour 5:99-105

Bigalke EH (1973) The exploitation of shellfish by coastal tribesmen of the Transkei. Ann Cape Prov Mus 9:159-175

$>$ Boero F (2001) Light after dark: the partnership for enhancing expertise in taxonomy. Trends Ecol Evol 16:266

> Bowman MF, Bailey RC (1997) Does taxonomic resolution affect the multivariate description of the structure of fresh- 
water benthic macroinvertebrate communities? Can J Fish Aquat Sci 54:1802-1807

Chapman MG (1998) Relationships between spatial patterns of benthic assemblages in a mangrove forest using different levels of taxonomic resolution. Mar Ecol Prog Ser 162: $71-78$

Clarke KR, Ainsworth M (1993) A method of linking multivariate community structure to environmental variables. Mar Ecol Prog Ser 92:205-219

Clarke KR, Green RH (1988) Statistical design and analysis for a biological effects study. Mar Ecol Prog Ser 46: 213-226

Clarke KR, Warwick RM (1994) Change in marine communities: an approach to statistical analysis and the interpretation. Plymouth Marine Laboratory, Plymouth

$>$ Dauvin JC, Gomes-Gesteira JL, Salvande-Fraga M (2003) Taxonomic sufficiency: an overview of its use in the monitoring of sublittoral benthic communities after oil spills. Mar Pollut Bull 46:552-555

De Biasi AM, Bianchi CN, Morri C (2003) Analysis of macrobenthic communities at different taxonomic levels: an example from an estuarine environment in the Ligurian Sea (NW Mediterranean). Estuar Coast Shelf Sci 58: 99-106

$>$ Defeo O, Lercari D (2004) Testing taxonomic resolution levels for ecological monitoring in sandy beach macrobenthic communities. Aquat Conserv Mar Freshw Ecosyst 14: $65-74$

Dumas P, Bertaud A, Peignon C, Léopold M, Pelletier D (2009) A 'quick and clean' photographic method for the description of coral reef habitats. J Exp Mar Biol Ecol 368:161-168

Ellis D (1985) Taxonomic sufficiency in pollution assessment. Mar Pollut Bull 16:459

Ferraro SP, Cole FA (1990) Taxonomic level and sample size sufficient for assessing pollution impacts on the Southern California Bight macrobenthos. Mar Ecol Prog Ser 67: 251-262

> Ferraro SP, Cole FA (1992) Taxonomic level sufficient for assessing a moderate impact on macrobenthic communities in Puget Sound, Washington, USA. Can J Fish Aquat Sci 49:1184-1188

Ferraro SP, Cole FA (1995) Taxonomic level sufficient for assessing pollution impacts on the Southern California Bight macrobenthos - revisited. Environ Toxicol Chem 14:1031-1040

Field JG, Clarke KR, Warwick RM (1982) A practical strategy for analysing multispecies distribution patterns. Mar Ecol Prog Ser 8:37-52

> Gomez-Gesteira JL, Dauvin JC, Salvande-Fraga M (2003) Taxonomic level for assessing oil spill effects on soft-bottom sublittoral benthic communities. Mar Pollut Bull 46: 562-572

Gray JS (2002) Species richness of marine soft sediments. Mar Ecol Prog Ser 244:285-297

- Gray JS, Aschan M, Carr MR, Clarke KR and others (1988) Analysis of community attributes of the benthic macrofauna of Frierfjord/Langesundfjord and in a mesocosm experiment. Mar Ecol Prog Ser 46:151-165

> Gray JS, Clarke KR, Warwick RM, Hobbs G (1990) Detection of initial effects of pollution on marine benthos: an example from the Ekofisk and Eldfisk oilfields, North Sea. Mar Ecol Prog Ser 66:285-299

Guzman A, Garcia CB (1996) Taxonomic aggregation and the detection of patterns in a tropical marine benthos data set. Rev Biol Trop 44(2B):907-910

- Guzman-Alvis AI, Carrasco F (2005) Taxonomic aggregation and redundancy in a tropical macroinfaunal assemblage of the southern Caribbean in the detection of temporal patterns. Sci Mar 69:133-141
James RJ, Smith MPL, Fairweather PG (1995) Sieve mesh size and taxonomic resolution needed to describe natural spatial variation of marine macrofauna. Mar Ecol Prog Ser 118:187-198

> Juanes JA, Canteras JC (1995) Monitoring of sewage outfalls in northern Spain: preliminary studies of benthic communities. Water Sci Technol 32:289-295

Karakassis I, Hatziyanni E (2000) Benthic disturbance due to fish farming analyzed under different levels of taxonomic resolution. Mar Ecol Prog Ser 203:247-253

> Lardicci C, Rossi F (1998) Detection of stress on macrozoobenthos: evaluation of some methods in a coastal Mediterranean lagoon. Mar Environ Res 45:367-386

Lasiak TA (1992) Contemporary shellfish gathering practices of indigenous coastal people in Transkei: implications for the interpretation of the archaeological record. S Afr J Ethnol 88:19-28

> Lasiak TA (1998) Multivariate comparisons of rocky infratidal macrofaunal assemblages from replicate exploited and non-exploited localities on the Transkei coast of South Africa. Mar Ecol Prog Ser 167:15-23

> Lasiak T (2003) Influence of taxonomic resolution, biological attributes and data transformations on multivariate comparisons of rocky macrofaunal assemblages. Mar Ecol Prog Ser 250:29-34

Legendre P, Gallagher ED (2001) Ecologically meaningful transformations for ordination of species data. Oecologia 129:271-280

> MacFarlane GR, Booth DJ (2001) Estuarine macrobenthic community structure in the Hawkesbury River, Australia: relationships with sediment physicochemical and anthropogenic parameters. Environ Monit Assess 72:51-78

Maurer D (2000) The dark side of taxonomic sufficiency (TS). Mar Pollut Bull 40:98-101

May RM (1990) Taxonomy as destiny. Nature 347:129-130

Mistri M, Rossi R (2001) Taxonomic sufficiency in lagoonal ecosystems. J Mar Biol Assoc UK 81:339-340

> Narayanaswamy BE, Nickell TD, Gage JD (2003) Appropriate levels of taxonomic discrimination in deep-sea studies: species vs family. Mar Ecol Prog Ser 257:59-68

Olsgard F, Somerfield PJ (2000) Surrogates in marine benthic investigations: Which taxonomic unit to target? J Aquat Ecosyst Stress Recovery 7:25-42

> Olsgard F, Somerfield PJ, Carr MR (1997) Relationships between taxonomic resolution and data transformations in analyses of macrobenthic community along an established pollution gradient. Mar Ecol Prog Ser 149:173-181

> Olsgard F, Somerfield PJ, Carr MR (1998) Relationships between taxonomic resolution, macrobenthic community patterns and disturbance. Mar Ecol Prog Ser 172:25-36

Pagola-Carte S, Urkiaga-Alberdi J, Bustamante M, Saiz-Salinas JI (2002) Concordance degrees in macrozoobenthic monitoring programmes using different sampling methods and taxonomic resolution levels. Mar Pollut Bull 44:63-70

- Roach AC, Jones AR, Murray A (2001) Using benthic recruitment to assess the significance of contaminated sediments: the influence of taxonomic resolution. Environ Pollut 112:131-143

Rumohr H, Karakassis I (1999) Comparison of multivariate patterns: different taxonomic levels in macrofaunal analysis versus sediment profiling imagery (SPI). Mar Ecol Prog Ser 190:125-132

Scheltema RS (1996) Describing diversity. Oceanus 39:16-18

Somerfield PJ, Clarke KR (1995) Taxonomic levels, in marine community studies, revisited. Mar Ecol Prog Ser 127: 113-119 
Stark JS, Riddle MJ, Simpson RD (2003) Human impacts in soft-sediment assemblages at Casey Station, East Antarctica: spatial variation, taxonomic resolution and data transformation. Austral Ecol 28:287-304

Terlizzi A, Fraschetti S, Guidetti P, Boero F (2002) The effects of sewage discharge on shallow hard substrate sessile assemblages. Mar Pollut Bull 44:544-550

Terlizzi A, Bevilacqua S, Fraschetti S, Boero F (2003) Taxonomic sufficiency and the increasing insufficiency of taxonomic expertise. Mar Pollut Bull 46:556-561

Terlizzi A, Anderson MJ, Bevilacqua S, Fraschetti S, WlodarskaKowalczuk M, Ellingsen KE (2009) Beta diversity and taxonomic sufficiency: Do higher-level taxa reflect heterogeneity in species composition? Divers Distrib 15:450-458

Thompson BW, Riddle MJ, Stark JS (2003) Cost-efficient methods for marine pollution monitoring at Casey Station, East Antarctica: the choice of sieve mesh-size and taxonomic resolution. Mar Pollut Bull 46:232-243

Torres Mendes CL, Tavares M, Soares-Gomes A (2007) Taxo-

Editorial responsibility: Jake Rice,

Ottawa, Canada nomic sufficiency for soft-bottom sublittoral mollusks assemblages in a tropical estuary, Guanabara Bay, Southeast Brazil. Mar Pollut Bull 54:377-384

> Urkiaga-Alberdi J, Pagola-Carte S, Saiz-Salinas JI (1999) Reducing effort in the use of benthic bioindicators. Acta Oecol 20:489-497

Vanderklift MA, Ward TJ, Jacoby CA (1996) Effect of reducing taxonomic resolution on ordinations to detect pollution-induced gradients in macrobenthic infaunal assemblages. Mar Ecol Prog Ser 136:137-145

> Warwick RM (1988) The level of taxonomic discrimination required to detect pollution effects on marine benthic communities. Mar Pollut Bull 19:259-268

- Warwick RM (1993) Environmental impact studies on marine communities: pragmatical considerations. Aust J Ecol 18:63-80

Warwick RM, Clarke KR (1993) Increased variability as a symptom of stress in marine communities. J Exp Mar Biol Ecol 172:215-226

Submitted: September 2, 2009; Accepted: January 29, 2010 Proofs received from author(s): April 30, 2010 